\title{
Use of plural in spoken English in an EFL context
}

\author{
Yusuf Sen a (i), Mesut Kuleli b * (1) \\ a Duzce University, Hakime Erciyas School of Foreign Languages, Düzce, 81100, Turkey \\ ${ }^{b}$ Duzce University, Hakime Erciyas School of Foreign Languages, Düzce, 81100, Turkey
}

Received 18 July 2017 | Received in revised form 15 September 2017 | Accepted 13 October 2017

\begin{abstract}
The aim of this study is to determine students' use of plural in speaking in an EFL context. To this end, 48 students' speaking exams, which were recorded during the oral exams in 2014-2015 academic year, were transcribed by the researchers and the students' use of plural was analyzed. It is important to note that not all the input was obtained from only one exam, but rather a progressive use of plural in English was analyzed with the data obtained from three different exams. As a result of the analysis, it was found that while students can use the plural appropriately with high-frequency words, they were found to use the singular form of an item in contexts where the plural form would be more appropriate. Considering the issue from a progressive perspective, it was found that this tendency did not persist in the long-run. While students from the ELT department were found to use plural appropriately, early level students were found to use plural "s" inappropriately. It was concluded that students' L1 (Turkish) and overgeneralization of rules in L2 might interfere with their use of plural in the early level, but the effect of $\mathrm{L} 1$ diminishes in the upper levels.

(C) 2017 EJAL \& the Authors. Published by Eurasian Journal of Applied Linguistics (EJAL). This is an open-access article distributed under the terms and conditions of the Creative Commons Attribution license (CC BY-NC-ND) (http://creativecommons.org/licenses/by-nc-nd/4.0/).
\end{abstract}

Keywords: Spoken English; plural in English; EFL context; L1 interference

\section{Introduction}

Corpus studies in English have been popular recently. The general purpose of those studies is to ensure that foreign language learners are directed to learn English as a foreign language in the order that native speakers of English learn it. While there are native use corpus studies, it is also possible to see non-native use corpus studies in the related literature. These corpus studies do not only provide a guidance for teachers of English as a foreign language, but also for publishers that take native and non-native corpus studies as the basis in material design.

This study was conducted to investigate whether foreign language learners of English conform to the corpus studies in spoken English in terms of their speaking skill. There are not only general corpus studies but also specific studies on written

\footnotetext{
* Corresponding author name. Tel: 03805421163

E-mail address: mesutkuleli@duzce.edu.tr

http://dx.doi.org/.......
} 
and spoken English. Aijmer and Altenberg (2014) state that a corpus study on spoken English conducted by a team led by Jan Startvik in 1975 has been the inspiration behind many spoken corpus studies of English since then. Despite all corpus studies and learning materials designed based on these studies, foreign language learners of English still have problems in speaking. These problems are not only about fluency but also have a lot to do with accuracy in speaking (Housen \& Kuiken, 2009). Use of plural was determined to be one of the leading problems of accuracy in speaking in an EFL context. In their study, Luk and Shirai (2009) argued that while English learners of Spanish origin can learn plural -s in the order that native speakers of English learn, those of Korean or Japanese origin learn this morpheme later than the natural order as suggested by Bailey, Madden and Krashen, (1974). This finding brings the issue of L1 interference into the limelight assuming that while English and Spanish are in the same language family, Korean and Japanese are in a language family different from English.

\subsection{Use of "Plural" in Native Corpus Studies}

There are some rules governing the use of plural suffix $-\mathrm{s}$ in English. Biber, Conrad and Leech (2002) state that despite some irregular nouns and those borrowed from other languages, most of the nouns in English are made plural with the suffixes -s, -es and -ies. DeCapua (2008) states that native speakers of English add the plural inflection -s,-es and -ies to regular nouns, however there are some irregular nouns for which only vowels change to make them plural besides certain nouns that do not change form or do not take any inflection in making plural such as sheep. DeCapua (2008) further adds that some nouns borrowed from other languages such as curriculum cannot be added the plural inflection, but rather they are made plural with the change of the last letters -um into -a sound (curriculum-curricula). However, says DeCapua (2008), because these exceptions are few in number, it should not pose any difficulties to speakers and learners of English either in ESL or EFL contexts.

It was in 1973 that Brown conducted a corpus study on the acquisition of grammatical morphemes. Brown (1973) found that English plural $-\mathrm{s}$ is learned when native speakers of English are somewhere around 30 months old. According to Brown (1973), native speakers of English first learn to use the present progressive morpheme "ing", followed by the prepositions "in" and "on". Of the 14 grammatical morphemes put forward by Brown (1973) to be learned by native speakers of English in a sequence, the regular plural morpheme -s is learned on the fourth rank, and Brown (1973) adds that those grammatical morphemes are learned in a sequence by native speakers regardless of their family background. Villiers and Villiers (1973) confirmed Brown's findings further suggesting that learning the regular plural -s at an early stage of language development cannot be attributed to the ease of using this morpheme or frequency of use by parents, but rather there is a natural sequence in learning morphemes by native speakers of English. 
Berko (1958) conducted a study on young children between the ages of 2,5 and 7 . In this study, participants were shown some low-frequency nouns besides high-frequency nouns and asked to make them plural and pronounce the words in their plural form. There was no difference in the results gender-wise, however, first graders performed better than pre-school children in low-frequency nouns. Berko (1958) reported that no matter how familiar nouns may sound to children, they can correctly add the $-\mathrm{s},-\mathrm{z}$ and $-1 z$ sounds to the nouns to make them plural, showing that native speakers can make overgeneralization of rules that they have learned and acquired to survive in conditions they are not familiar with.

\subsection{Use of "Plural" by Non-native Speakers of English}

While there are certain underlying rules as regards the accurate use of plural $-\mathrm{s}$ in native speaker corpus, it is not uncommon that non-native speakers of English cannot use this suffix accurately in speaking. Mauranen (2012) states that non-native speakers of English tend to forget to add the plural suffix to a noun or they add -s to irregular nouns even in academic contexts. This finding makes it imperative that EFL learners should be explicitly taught to use plural in English while it is also possible for them to learn to use this suffix implicitly. Başöz and Aydın (2001) report that EFL students' misuse of plural forms in writing can be regarded as mistakes rather than errors. This finding shows that even in writing, which is less spontaneous than speaking, EFL learners have problems in plural forms of nouns.

The problems with plural $-\mathrm{s}$ suffix are common, and the reasons for this cannot be attributed to a single cause, but there are various reasons for the inaccurate use of this suffix by non-native speakers of English. Peyman (2014) found that one of the inaccuracies in EFL contexts stems from plural use of nouns. Peyman (2014) identified two types of errors in the use of plural, one of them using a singular noun where plural form would be more appropriate, and the other one using a plural noun where a singular form would be more appropriate. Bailey, Madden and Krashen (1974) found that there is a natural sequence in adults' learning English, and the mistakes adults make also follow this natural sequence, with plural form being one of the earliest learned forms. This, however, does not guarantee that adults do not make any mistakes in plural forms in their conversations. Ting, Mahadhir and Chang (2010) analyzed the oral skills of university students in an EFL context and found that mistakes in plural forms are one of the most frequently observed problems with foreign language learners at university level, particularly among less proficient users of English; however, they also came up with the suggestion that accuracy in oral skills developed as the students' English level developed towards the end of the academic year. In another EFL context, Jing, Tindall and Nisbet (2006) found that Chinese students had great difficulties forming plural nouns in English and the authors attributed this phenomenon to L1 interference.

As can be seen in these findings, even though plural nouns of English are taught at the very beginning based on course books, users of English still have difficulties in 
plurals. Even though it cannot be the sole reason, this can be partly attributed to what learners of English in an EFL context already bring to the learning environment with themselves; the role of L1 interference. Pallotti (2010) states that deviation from L2 rules cannot simply be explained by L2 itself, but rather learners of L2 tend to develop an interlanguage in L2 learning process. Lado (1957) posited the term Contrastive Analysis stating that when the notions in two languages are similar to each other, L2 forms and functions can be learned more easily, however, when two notions between L1 and L2 are dissimilar, they cannot be learned so easily. Turkish and English do not belong to the same language family, and formation and function of the plural are different in those two languages. Demir (2006) put forward that all singular nouns are made plural with the same plural suffix in Turkish. However, unlike Turkish, there are certain irregularities in English nouns to make them plural. Eker (2003) states that in Turkish when a number is used as an adjective before a noun, the plural suffix cannot be added to the nouns. This is also contrary to the process in English, in which the plural suffix is added to the nouns after numbers as adjectives. When English learners of Turkish origin try to learn English in an EFL context, they may develop an interlanguage, with some forms from Turkish and some forms from English. Considering this interlanguage from contrastive analysis perspective, English learners of Turkish origin might have difficulties in plural forms in English.

\section{Method}

In this part of the study, participants, data collection procedure, and data analysis are given.

\subsection{Participants}

The participants of this study were prep school students at Düzce University, Turkey. The total number of students was 255 in 2014-2015 academic year. These students received 24 hours of English classes per week for 17 weeks in the first semester and 16 weeks in the second semester as part of the preparatory school curriculum. In this curriculum, students are taught basic English through a course book that integrates four skills for the first 17 weeks of the academic year. From the second semester onwards, students are given separate skills courses, namely Reading \& Writing and Listening \& Speaking for ten hours per week for each course. Therefore, while students are taught speaking skills in a course book in the first semester, more emphasis is put on this major skill in the second semester with the Listening \& Speaking course. The first oral exam was given at the end of the 9th week; the second oral exam was given at the end of the 17th week; and the third oral exam was given at the end of the 25 th week. Of those 255 students, 48 of them were chosen purely randomly to collect data from. In the first oral exam, 16 students' speech was chosen for analysis. Students finished only the first level of a course book, so they were supposed to have mastered A1 level in English in accordance with the 
guidelines of CEFR. In the second oral exam, another 16 students' speech was chosen for analysis. By the time of the second oral exam, students had finished the second level of the same course book, and so they were supposed to have mastered A2 level in English. Another 16 students were chosen for the third oral exam analysis. After the second oral exam, besides 4 hours of course book instruction per week, 10 hours were allocated to reading / writing, and another 10 hours were allocated to listening / speaking skills, therefore students used skills books besides a main course book in the eight weeks between the second oral exam and third oral exam. 16 students for analysis of each oral exam were chosen purely randomly. It is important to note that prep school is a must for only English Teaching Department students while all other students choose to study at prep school optionally. 3 students were chosen from ELT department to collect data from. The remaining 45 students were from the classes that took English preparatory lessons optionally. While the students from ELT department were in upper level of English, 6 of the students from other classes were in pre-intermediate level, and 39 of them were in the beginner level based on the placement exam results administered at the beginning of the academic year.

\subsection{Data collection procedure}

The oral exams in preparatory school were video-recorded in 2015-2016 academic year with students' consent. As stated in section 2.1, 16 students' oral exam records were chosen purely randomly for analysis of their improvement in oral skills in each speaking exam. It is important to note these 16 students were not the same students in three different oral exams on the grounds that the aim of this study was not to observe individual improvement but rather a structural improvement of a group considered to be representative of the universe in the study. The records of the oral exams were transcribed by the researchers of this study. The data obtained through transcriptions were divided into three parts: the first part was the data from the first oral exam; the second part was the data from the second oral exam; and the third part was the data from the third oral exam to determine the improvement of students in the use of plural in spoken English in a clear manner.

\subsection{Data Analysis}

A qualitative approach was adopted in data analysis in that the aim was to describe a situation and gain insight to a practice from individual responses, and the data was explained from a small sample group. The reason behind the qualitative design of this study was that a single unit was investigated in-depth over a period of time. The mistakes of students with the use of plural forms of nouns were found from transcriptions. The findings were divided into categories based on the nature and level of the mistake, for which percentage statistics was used. The findings were reported based on whether these mistakes occurred in the first, second or third oral exam. 


\section{Results}

This section of the study is divided into three parts. The first part is concerned with the common mistakes students made in the lower level; the second part deals with the mistakes students made in the pre-intermediate level; and the third part covers the mistakes students made in the upper level. The reason for dividing the findings in this way is to show whether students developed their accuracy in plural use in spoken English or if the mistakes persisted to upper levels in their learning process.

The results of this study point to the fact that while learners of English in an EFL context made a lot of mistakes with plural form of nouns in spoken English in early levels of their learning process, these mistakes were reduced as the learners advanced to pre-intermediate level. Upon reaching an upper level, learners or English made the fewest number of mistakes in the use of plural in speaking. Table 1 shows the distribution of those mistakes according to level.

Table 1. Distribution of mistakes according to

\begin{tabular}{lll} 
Level & Number of mistakes & Percentage \\
\hline Early level & 14 & $58.33 \%$ \\
Pre-intermediate & 8 & $33.33 \%$ \\
Upper LEvel & 2 & $8.34 \%$ \\
\hline
\end{tabular}

As can be seen in Table 1, of the 24 cases in total, 14 (58.33\%) cases were found to include mistakes with plural form of nouns in the early level; this number was 8 (33.33\%) in pre-intermediate level, and it was only 2 (8.34\%) in the upper level. Besides levels, the distribution of mistakes according to English grammar rules was also found. Table 2 shows the distribution of mistakes according to grammar rules.

Table 2. Distribution of mistakes according grammar rules

\begin{tabular}{lll} 
Grammar rule & Number of mistakes & Percentage \\
\hline After numeral adjectives & 10 & $41.67 \%$ \\
After determiners or quantifiers & 8 & $33.33 \%$ \\
Generic meaning with zero article & 5 & $20.83 \%$ \\
Irregular nouns & 1 & $4.17 \%$ \\
\hline
\end{tabular}

As can be seen in Table 2, of those 24 cases, 10 (41.67\%) were related to using the singular form of a noun inappropriately after numeral adjectives. Of those 10 misuses of plural form, 9 (90\%) were observed in the early level while only 1 (10\%) of them came out in the pre-intermediate level. Of the 24 mistakes found in this study related to use of plural in spoken English, 8 (33.33\%) of them turned out to be after determiners or quantifiers. Of those 8 mistakes, 4 (50\%) were in the early level; 3 $(37.5 \%)$ were in the pre-intermediate level; and finally only $1(12.5 \%)$ was in the upper level. $5(20.83 \%)$ mistakes in total were related to inappropriate use of a singular form of the nouns with generic meaning with zero article. Of those 5 mistakes, 1 (20\%) was found in early level; 3 (60\%) were found in pre-intermediate level; and 1 (20\%) was 
found in the upper level. Finally, only 1 (4.17\%) mistake was related to misuse of plural form with irregular nouns and this appeared only in pre-intermediate level. Therefore, while the number of mistakes with plural use in spoken English decreased as students' level improved, the nature of the mistakes also changed. While students in early level tended to make mistakes with inappropriate use of a singular form of the noun after numeral adjectives and quantifiers or articles, students tended to make mistakes with plural use in generic nouns with zero article as their level improved.

\subsection{Findings in the early level}

The analysis showed that students tended to make frequent mistakes in plural use of nouns in spoken English in the early level. Below are some representative findings of the analysis of transcriptions in the early level:

Case 1: Student: Once in two. A week. Yok two week*.

Case 2: Student: I know Bilge. We are. Same course. Last year. I know Alper er. I guess. We are same high school. Two year*. But I don't me. I didn't meet Alper.

Case 3: Student: Yes I have two sister*.

Case 4: Student: Yes. But yesterday it is not really problem, just I couldn't do two question*.

Teacher: Two questions [in the exam,]. The writing one?

Student: [yes, yes].

Case 5: Student: My mother is housewife and my father is retired. I have a brother and I have four sisters. I have got eight nephew*.

Case 6: Teacher: How long does it take to go to Istanbul from Düzce? How long does it take?

Student: Four month*.

Case 7: Teacher: Did you go to Akçakoca?

Student: Yes. Four year*.

Case 8: Teacher: When?

Student: Two day*.

Case 9: Student: I want, I really want two child*.

As can be seen in the 9 cases above, the most frequent mistake in plural use of nouns in spoken English in an EFL context turned out to be using the singular form of the nouns after numeral adjectives. Biber, Conrad and Leech (2002) state that numeral adjectives are followed by plural forms of nouns in English. Swan (1995) also exemplifies that plural forms of the nouns follow numbers used as adjectives. While the plural form of the nouns should have been used after numeral adjectives, learners tended to use the singular forms. In case 1 , "two week" should have been used as 
"two weeks"; in case 2, "two year*" should have been used as "two years"; in case 3, "two sister" should have been used as "two sisters"; in case 4, "two question*" should have been used as "two questions"; in case 5, "eight nephew*" should have been used as "eight nephews"; in case 6, even though the answer of the student does not fit in with the discourse, "four month*" should have been used as "four months"; in case 7, "four year*" should have been used as "four years"; in case 8, "two day" should have been used as "two days"; and in case 9, "two child*" should have been used as "two children". It is important to note that in some of these cases, students' using singular nouns inappropriately where the plural form would be appropriate is not the only element that disrupts accuracy, but because of the scope of this study, only misuse of plural forms in spoken English has been covered. Below are some other cases from the early level learners of English:

Case 10: Teacher: What is bad about your friend? Is he always good?

Student: No . She - He have other friend*.

Case 11: Student: OK. I like big shopping because it's easy. It's have all company*.

Case 12: Student: Have speed neighborhoods but not always sometimes bad. Its

good people. They are helpful. We have a lot of park*. We we are playing football

match.

Case 13: Student: After I child, we don't have big build. Everywhere tree* and

flowers but now no any tree*. I was school by bus but after we go to, we want to, we went school.

Case 14: Student: I love literature because I love poem*.

Teacher 2: Do you read poems?

Student: Yes. Love poems.

Even though the mistakes in these cases above may not seem as striking as the ones in cases from 1 to 9, they still disrupt accuracy in speaking. In case 10, "other friend*" should have been used as "other friends" because Biber, Conrad and Leech (2002) state that after determiners such as other, plural forms of nouns follow. In case 11, "all company*" should have been used as "all companies" since Biber, Conrad and Leech (2002) suggest that if the quantifier all is followed by a countable noun, that noun is used in plural form. In case 12, "a lot of park" should have been used as "a lot of parks". Swan (1995) states that quantifying expressions are to be followed by plural forms of the nouns. In case 13, "no any tree*" should have been used as "no trees". The inaccuracy in case 12 is not only about the plural use of the noun, but because of the scope of the study, we will only deal with the misuse of plural forms. Biber, Conrad and Leech (2002) state that if the quantifier "no" is followed by a countable noun, that noun is used in plural form. There is a different misuse of plural forms in case 14 compared to the other 13 cases reported in this section. In the student's utterance "I love poem*", the plural form of the noun poem could have been 
more appropriate. It is important to note that when the teacher asks a corrective question "Do you read poems?" the student corrects himself saying "Love poems". According to Biber, Conrad and Leech (2002) when a generic countable noun is used with zero article referring to the whole class, this noun is used in plural form. Swan (1995) indicates that while generalizations can be given both in singular and plural forms, when there is no article before the noun, it is used in plural form.

\subsection{Findings in the Pre-Intermediate level}

The analysis showed that students also made mistakes with the plural use of nouns in spoken English in the supposedly pre-intermediate level. Below are some the findings of the analysis of transcriptions in the pre-intermediate level:

Case 15: Student: Because there are. er. a lot of old building*.

Case 16: Student: There are a lot of natural place* in Bolu. yeah. so beautiful.

Case 17: Student: You have two option* to change your university, one of them, you can go with your university point Yes, I don't have but I [have two option*.] Yes, yes, yes, I don't need because I have two option* to change my university. One of them it's with university point, YGS. One of them with the transcript.

In cases 15 to 17 , students used the singular from of the nouns where the plural form would be more appropriate. In case 15, "a lot of old building*" should have been used as "a lot of old buildings", and in case 16 "a lot of natural place*" should have been used as "a lot of natural places". Biber, Conrad and Leech (2002) state that the quantifier "a lot of" is followed by a plural form of the noun if that noun is countable. According to Swan (1995), when a quantifying expression is followed by a countable, that noun is used in plural form. In case 17, the student repeated the same misuse for three times successively in the same discourse. In this case, "two option*" should have been used "two options". Below are some other cases found in supposedly preintermediate level:

Case 18: Student: Yes, Unfortunately true. The womans*.

Teacher: What's unfortunate? Should the women like it or should the men not like it.

Student: ((Laughs)). Men should be like womans*. They shouldn't use the bad words. I'm feeling very bad. For example, it's not really big problem for me but someone, girls or womans*, womans* in the bus they are hear too, they hear, too. So it's problem. It's not really big problem for me because I'm using sometimes for example, when I'm happened angry. So I'm using bad word but womans* not like that, womans*, so it's. 
In case 18, the student used the plural form of the irregular noun woman as "womans*". It is important to note that the teacher asked a corrective question using the appropriate form "women", however the student persisted in using the inappropriate form "womans" five more times in the discourse after the corrective question of the teacher. Biber, Conrad and Leech (2002) state that a limited number of nouns are irregular in English and rather than adding the regular plural suffix, they are made plural with a change in a vowel in the noun and give the example of woman-women for these irregular nouns. Swan (1995) states that the plural form of the irregular noun "woman" is "women". Below are some other cases found in supposedly pre-intermediate level:

Case 19: Student: Read book*, watch movie*, TV series. Talk my friends, hang out my friends.

Case 20: Teacher: What makes a city boring? Why is it boring?

Student: Because, it's don't have café*, or shopping center*.

Case 21: Teacher: Do you read any books about your major?

Student: No. I read hip hop magazine*.

These cases include mistakes in the use of plural different from those in cases 1518. In cases 19-20-21, students used the singular form of nouns where it would be more appropriate to use their plural form. In case 19, "read book*, watch movie*" should have been used as "read books, watch movies". In case 20, "it don't have café, or shopping center*" should have been used as "cafés or shopping centers". In case 21 , "I read hip hop magazine*" should have been used as "I read hip hop magazines". The nouns in these cases are used in generic meaning with zero article. According to Biber, Conrad and Leech (2002) when a generic countable noun is used with zero article referring to the whole class, this noun is used in plural form. Below is the last case of mistake with the use of plural found in pre-intermediate level:

Case 22: Teacher: What's your plan in Erasmus? if you go?

Student: I go Erasmus, hmm, I can see other culture* and I can see new

place*. I can learn all related language*.

As can be seen in case 22 , the first mistake with a plural form was found after a determiner. While a plural form of the noun culture would be appropriate here, the student used the singular form after the determiner "other". Biber, Conrad and Leech (2002) state that after determiners such as other, plural forms of nouns follow. Biber, Conrad and Leech (2002) also suggest that if the quantifier "all" is followed by a countable noun, that noun is used in plural form, therefore, the student's utterance "all related language*" should have been used as "all related languages". Another mistake with the use of plural can be seen in "I can see new place*". According to Biber, Conrad and Leech (2002) when a generic countable noun is used with zero article referring to the whole class, this noun is used in plural form, hence the student 
should have used the plural form of the generic noun place in this discourse as in "I can see new places".

\subsection{Findings in the upper level}

The analysis showed that students, though very few in quantity, also made mistakes with plural use of nouns in spoken English in the supposedly upper level. Below are the only two findings obtained from the analysis of transcriptions in the upper level:

Case 23: Student: Let me think. Sometimes people talk on the phone loudly and it's really noisy. People don't like that, other peoples* but I don't have experience for this but it can be, if we don't follow the rules, it can be, you can other peoples* maybe.

As can be seen in case 23, the student used the plural form of the irregular noun person as people appropriately in two instances, but that student misused the plural form of the same noun when it followed the determiner other. Biber, Conrad and Leech (2002) state that after determiners such as other, plural forms of nouns follow. Biber, Conrad and Leech (2002) further state that some plural-only nouns such as people or police can be confusing because they may seem to be singular but indeed they are plural nouns. In this case, the student used "other peoples*" which should have been used as "other people". Swan (1995) states that the plural form of the irregular noun "person" is "people". Even though it is also possible to use the noun people in plural form as peoples, it takes on a different meaning referring to a race, yet the context here makes it clear that the student is not referring to people of a race but rather to the plural form of the noun person. Below is the last case of a mistake with plural use found in upper level:

Case 24: Student: Thirty-five. I usually use shopping websites, social media website*. I love cars and motorcycle*. I look motorcycle and car picture* and options.

As is clear from the case 24, the student supposed to be in the upper level misused the generic nouns "social media website*, motorcycle* and motorcycle and car picture*" in this context. It can be understood from the context that the student is referring to the generic meaning of these nouns with zero article, which is used in plural form according to Biber, Conrad and Leech (2002). Therefore, the student should have used the plural forms of these nouns in this case.

\section{Discussion}

The mistakes students made with plural nouns after numeral adjectives in spoken English can be attributed to L1 interference. As aforementioned in section 1.2, Eker (2003) stated that nouns are not added a plural suffix after numeral adjectives in 
Turkish, which is contrary to the rule in English. The most common mistake was found to be using a singular noun after a numeral adjective particularly in the early level. This brings the issue of L1 interference (Turkish in our study) to the limelight. Selinker (1972) states that native language transfer is one of the components that shapes the interlanguage. Tarone (2012) states that while native language transfer may be a contributing factor in interlanguage as contrastive analysis hypothesis puts forward (Lado, 1957), it is far from being the sole reason. Therefore, native language transfer can be seen only in the mistakes after numeral adjectives, suggesting that learners transfer from their L1 more in early levels of learning English. Jia (2003) found that Mandarin speaking children who immigrated to the US learned to use the plural morpheme in English much later than their native speaker counterparts, and this was attributed to L1 interference. The findings by Jia (2003) are compatible with the results of this study in that the participants in this study also transferred from their L1 in using the plural morpheme after numerical adjectives. Another study confirming the results of this study as regards L1 interference was conducted by Scott and Tucker (1974) who analyzed Arab students' errors in English both in writing and speaking skills and concluded that the errors in grammatical morphemes may have stemmed from L1 interference. As can be seen, L1 interference is not limited to speaking skill only, but it can manifest itself even in writing skill. Su Feng (2012) investigated English writings of learners from Hong Kong and found a strong relationship between the grammatical errors students do and L1 interference. Bhela (1999) also found a strong L1 interference in students' English writing. Nemati and Taghizade (2006) came up with the conclusion that when L1 and L2 are not similar to each other, L1 interference leads learners to make up inappropriate L2 discourses.

The mistakes found with regard to using singular forms of countable nouns after quantifiers or determiners were also quite a few in number. This can be attributed to overgeneralization of target language rules as suggested by Selinker (1972). Because uncountable nouns are not added a plural suffix after the quantifier a lot of as suggested by Biber, Conrad and Leech (2002), learners might have overgeneralized this rule and extended this to countable nouns. It would be plausible to think that students hear and learn "a lot of money" much earlier in a classroom setting as compared to "a lot of parks, a lot of buildings". Seeing that "a lot of" is followed by a singular noun as is the case with "a lot of money" without any consideration of whether it is a countable or uncountable noun, students may overgeneralize this even in countable nouns if they do not have a good command of countable and uncountable nouns in English. Overgeneralization of target language rules can also be shown as the reason for inappropriate use of the plural suffix $-\mathrm{s}$ with an irregular noun like woman. Even though EFL learners are explicitly taught these limited number of irregular nouns, they can still make mistakes in making those nouns plural on grounds that most of the time they add the plural suffix to regular nouns, which are fairly high in percentage in English. Berko (1958) when students learn English morphemes, they may "consciously or unconsciously generalize those rules in other contexts" (p. 150). While this ability to generalize morphemes can be to the advantage 
of the learners, it may turn out to be a disadvantage if they overgeneralize. In an experimental study on learning English morphemes by non-native speakers, Palermo and Eberhart (1968) found that the errors in irregular pairs stemmed from the overgeneralization of regular forms. Marcus (1995) states that learners of English tend to overgeneralize the morphological structures and overgeneralization of the past forms of irregular verbs in English is governed by the same rules applying to the overgeneralization of the plural forms of irregular nouns. Some other studies in literature found similar results to this study stating that learners of English, not only in EFL contexts, but also even in ESL contexts, have a tendency to overgeneralize the morphemes in English. Taylor (1975) stated that learners tended to overgeneralize the rules of the target language and transferred learning strategies even in ESL contexts. This shows that overgeneralization of morphemes is not uncommon even in ESL contexts.

Another group of mistakes found in this study turned out to be using the singular form of a noun in generic nouns with zero article. As suggested by Biber, Conrad and Leech (2002), if a countable noun is used in generic meaning, it is generally used with a / an articles. If this noun is used with zero article, then it is used in plural form. This can also be attributed to L1 interference because in Turkish it is most frequent to use singular form of a countable noun with zero article.

In this study, the term "mistake" rather than "error" was used for inappropriate use of plurals in speaking. Ellis (1997) states that when an inappropriate use stems from a gap in learners' knowledge, it can be called an "error"; however, when this inappropriateness comes out once in a while, then it can be called a "mistake". From the cases given in section 3 in this study, it can be seen that while students can use a plural noun appropriately after numeral adjectives or quantifiers in some instances, they make mistakes in some other instances.

\section{Conclusion}

Language learners in an EFL context are already deprived of the opportunities to practice the target language in their daily lives. Therefore, learners develop an interlanguage, a language made up of their mother tongue and the target language. When L1 and L2 are dissimilar to each other, this inevitably brings about a disadvantage caused by L1 interference, as was the case in this study. Besides L1 interference, learners in an EFL context may also try to benefit from overgeneralization of rules. These both issues lead to lack of accuracy in spoken English. Despite the long-held controversy of accuracy versus fluency, the analysis of video-records and transcribed texts showed that in early level, when students made most mistakes in plural form, they were already far from fluency, which implies that lack of accuracy is accompanied by lack of fluency. This study showed that students' mistakes in plural forms in speaking decreased as they improved their English level. This, however, did not bring about accuracy in other grammatical forms of English in speaking. 
In this study, 48 samples were analyzed for data collection. Further studies on the issue can be conducted with a larger sample group. While there are extensive studies in literature on students' improvement in writing or listening skills, the number of studies dealing with the improvement of accuracy in spoken English is far from being adequate. It is hoped that this study will enable English teachers in EFL contexts to gain insights into learners' problems with plural nouns and approach these problems more consciously based on the factors leading to such problems discussed in this paper. More extensive studies covering general grammar accuracy rather than only one morpheme can be conducted, which would serve as a guide not only to teachers of EFL contexts but also to material designers and curriculum developers.

\section{References}

Aijmer, K., \& Altenberg, B. (2014). English corpus linguistics. New York: Routledge.

Bailey, N., Madden, C., \& Krashen, S. D. (1974). Is there a "natural sequence" in adult second language learning?. Language learning, 24(2), 235-243.

Başöz, T., \& Aydın, S. (2011). An analysis of the grammatical mistakes made by advanced EFL writers. E-Journal of New World Sciences Academy, 6(2), 296-306.

Berko, J. (1958). The child's learning of English morphology. Word, 14(2-3), 150-177.

Bhela, B. (1999). Native language interference in learning a second language: Exploratory case studies of native language interference with target language usage. International Education Journal, 1(1), 22-31.

Biber, D., Conrad, S., \& Leech, G. (2002). Longman student grammar of spoken and written English. Essex: Pearson.

Brown, R. (1973). A first language: the early stages. Cambridge, MA: Harvard University Press.

De Villiers, J. G., \& De Villiers, P. A. (1973). A cross-sectional study of the acquisition of grammatical morphemes in child speech. Journal of Psycholinguistic Research, 2(3), 267278.

DeCapua, A. (2008). Grammar for teachers: A guide to American English for native and Nonnative speakers. New York: Springer Science \& Business Media.

Demir, T. (2006). Türk dilbilgisi. Ankara: Kurmay.

Eker, S. (2003). Çă̆daş Türk dili. Ankara: Grafiker.

Ellis, R. (1997). SLA research and language teaching. New York: Oxford University Press.

Housen, A., \& Kuiken, F. (2009). Complexity, accuracy, and fluency in second language acquisition. Applied Linguistics, 30, 461-473.

Jia, G. (2003). The acquisition of the English plural morpheme by native Mandarin Chinesespeaking children. Journal of Speech, Language, and Hearing Research, 46(6), 1297-1311.

Jing, L., Tindall, E., \& Nisbet, D. (2006). Chinese learners and English plural forms. Linguistics, 1, 127-147.

Lado, R. (1957). Linguistics across cultures; applied linguistics for language teachers. With a foreword by Charles C. Fries. Ann Arbor: University of Michigan press.

Luk, Z. P. S., \& Shirai, Y. (2009). Is the acquisition order of grammatical morphemes impervious to L1 knowledge? Evidence from the acquisition of plural-s, articles, and possessive's. Language Learning, 59(4), 721-754. 
Marcus, G.F. (1995). The acquisition of the English past tense in children and multilayered connectionist networks. Cognition, 56(3), 271-279.

Mauranen, A. (2012). Exploring ELF: Academic English shaped by non-native speakers. New York: Cambridge University Press.

Nemati, M., \& Taghizade, M. (2006). Exploring similarities and differences between L1 and L2. IRJABS, 4(9), 2477-2483.

Palermo, D.S., \& Eberhart, V.L. (1968). On the learning of morphological rules: An experimental analogy. Journal of Verbal Learning and Verbal Behavior, 7(2), 337-344.

Pallotti, G. (2010). Doing interlanguage analysis in school contexts. In I. Bartning, M. Martin, \& I. Vedder (Eds.), Communicative proficiency and linguistic development: Intersections between SLA and language testing research, (pp.159-190). Essex: Eurosla.

Peyman, H. (2014). Iranian EFL learners' problems in using English singular and plural nouns. International Journal of Language Learning and Applied Linguistics World, 6(2), 224-244.

Scott, M. S., \& Tucker, G. R. (1974). Error analysis and English-Language strategies of Arab students. Language learning, 24(1), 69-97.

Selinker, L. (1972). Interlanguage. IRAL-International Review of Applied Linguistics in Language Teaching, 10(1-4), 209-232.

Su Feng, L. (2012). The acquisition of plurals in English writings by Hong Kong students. (Unpublished master's thesis). The University of Edinburg, Edinburg, England.

Swan, M. (1995). Practical English usage. New York: Oxford University Press.

Tarone, E. (2012). Interlanguage. The Encyclopedia of Applied Linguistics. 747-752.

Taylor, B. P. (1975). The use of overgeneralization and transfer learning strategies by elementary and intermediate students of ESL. Language learning, 25(1), 73-107.

Ting, S. H., Mahadhir, M., \& Chang, S. L. (2010). Grammatical errors in spoken English of university students in oral communication course. GEMA: Online Journal of Language Studies, 10(1), 53-70.

\section{Copyrights}

Copyright for this article is retained by the author(s), with first publication rights granted to the Journal.

This is an open-access article distributed under the terms and conditions of the Creative Commons Attribution license (CC BY-NC-ND) (http://creativecommons.org/licenses/by-nc-nd/4.0/). 